Eskimos. In 1961 Jensen briefly reported the occurrence of sucrose malabsorption in a female Greenlander (with a Danish spouse) and her three children. His observations attract new interest in view of our findings. Though a certain selection in our case material was inevitable, since several infants were referred to the study group because of unexplained diarrhoea, the number of cases with sucrose malabsorption far exceeded the incidence expected from other studies.

Nevertheless, the incidence of lactose malabsorption in Greenland is much higher, from 54 to $88 \%$ depending on the racial purity of the subjects studied (Gudmand-Høyer et al., 1972). However, lactase deficiency is a feature which Greenlanders share with the majority of the populations in Asia and Africa (Rosensweig, 1971), whereas a $10 \%$ incidence of sucrose malabsorption does not seem to have been reported from anywhere else in the world.

One may speculate whether the fact that man in the Arctic regions has sustained himself on predominantly animal food for thousands of years may have tended to deprive him of sucraseisomaltase as a "negative" adaptive response, since sucrose and isomaltose (in starch) are of vegetable origin. Similarly, no need has existed for lactase activity after the weaning period until recently, because dairy products cannot be processed in the Arctic climate.

Lactase deficiency in Greenlanders seems to arise in childhood after the weaning period (Gudmand-Hфyer et al., 1972). In contrast, sucrose malabsorption apparently exists from birth. It may have important clinical consequences in early life. Thus three of the infants studied by us presented with chronic diarrhoea and severe malnutrition. In the most severe case the patient spent 18 months in hospital from the 10th week of life. $\mathrm{He}$ was the only infant to suffer both sucrose and lactose malabsorption. When these diagnoses were established (as a result of the present investigation) he was put on a lactosesucrose-poor diet, which led to a rapid improvement.

The death rate from "enteritis" among infants below 1 year of age in Greenland is several times higher than in Denmark. Hitherto unrecognized sucrose malabsorption may be a contributory cause of this difference or the reason for it.

Among the older children and adults with sucrose malabsorption in this study half (8) suffered from chronic or intermittent diarrhoea. In several instances diarrhoea started during infancy when cows' milk enriched with cane sugar was given. A few subjects had noticed that sweets produced diarrhoea. The fact that almost half of the subjects in this series had no gastrointestinal complaints despite regular sucrose consumption is not extraordinary. A similar observation was made by Anderson et al. (1963). Similarly, it is well known that lactase-deficient individuals often tolerate even fairly large amounts of milk without any distress.

This work was supported by grants from Den Lægevidenskabelige Forskningsfond for Storkøbenhavn, Færøerne og Grønland, P. Carl Petersens Fond, and the Danish Foundation for the Advancement of Medical Science.

\section{References}

Anderson, C. M., Messer, M., Townley, R. R. W., and Freeman, M. (1963). Pediatrics, 31, 1003.

Asp, N.-G., et al. (1972). To be published.

Gudmand-Høyer, E., McNair, A., and Jarnum, S. (1972). To be published.

Jensen, P. E. (1962). Acta Paedicatrica Scandinavica, 51, 227.

Rosensweig, N. D. (1971). Gastroenterology, 60, 464.

\title{
Outpatient Treatment Trial of Mild and Severe Hypertension
}

\author{
K. L. STUART, C. MACIVER, J. A. NICHOLSON
}

British Medical fournal, 1972, 2, 21-24

\section{Summary}

Not much is known about the feasibility or the advantages of treatment of subjects with only mild hypertension. There are also many unresolved problems in the outpatient management of hypertension of any severity. In this study an analysis is made of the results of a controlled treatment trial of 56 subjects with mild hypertension, 26 of whom were treated with active drug and 30 initially with placebo, and a treatment programme involving 81 patients with moderate or severe hypertension, all of whom received treatment with active drug. The drugs used in this study were bethanidine, debrisoquine, and guanethidine.

Follow-up for 12 months or more was achieved in $87 \%$ of individuals admitted to the study with mild hypertension and in $80 \%$ with severe hypertension. Many subjects with only mildly raised blood pressure were found to have cardiac enlargement on chest $x$-ray (up to

Department of Medicine, University of the West Indies, and University Hospital, Jamaica

K. L. STUART, F.R.C.P., Professor of Medicine

C. MACIVER, M.R.C.P., Consultant

J. A. NICHOLSON, M.R.C.P., Senior Registrar

$45 \%$ ) and left ventricular hypertrophy on electrocardiogram (up to $51 \%$ ). Rapid rates of rise of blood pressure were observed in many placebo-treated subjects; but good blood pressure control was achieved in 63 out of 104 patients $(61 \%)$ receiving active drug in both the mild and the severe hypertension groups. The drugs used showed approximately equal effectiveness in controlling blood pressure.

\section{Introduction}

Clinical medicine has tended to concern itself principally with the treatment of the complications or catastrophic end-stages of chronic diseases rather than with their prevention. The patient with heart attack or stroke is treated but little is done to reduce the frequency of these occurrences, although there is adequate evidence that early recognition and effective and sustained treatment of hypertension would achieve this.

That hypertension is one of the commonest and most potent precursors of cardiovascular disease is beyond doubt. Nor is there any reason to dispute that patients with either severe or moderate hypertension benefit from treatment. What is not so well known is whether and to what extent the same benefits may accrue from the treatment of mild hypertension before organ damage has occurred. Freis (1969) pointed out that it is here that the greatest potential for lowering hypertensive 
morbidity and mortality must rest. Awaiting the onset of target-organ involvement before instituting treatment can hardly be reasonable if the major goal in the management of hypertension is to avoid its cardiovascular consequences.

There are many problems to be grappled with, however, in the management of hypertension of any severity. High on the list is the fact that because of its essentially symptomless nature only a fraction of those suffering from the disorder are ever recognized or receive any form of treatment. In addition, it is well known that most of those who come under treatment often receive this only episodically and inadequately. Also, because the side effects of effective treatment may be more severe than the symptoms of the untreated disorder the proportion of patients who will accept adequate and continuing treatment tends to fall significantly with time. For these reasons there are few communities in which the management of hypertension can be considered to be adequate. Hospital and generalpractitioner services provided on an individualistic basis to patients with symptoms cannot be expected to cope with the problem as a whole. The need for programmes of detection and treatment of this and a number of other chronic disorders is increasing, and there are good reasons for such programmes to be based on special clinics where facilities can be provided for the management of large numbers of affected individuals on a community basis.

A further consideration, particularly relevant in the tropics and in most developing countries, is that acute shortages of hospital beds make it necessary for a greater proportion of patients to be treated entirely on an outpatient basis than in Western communities. It commonly happens that only those patients with advanced and often terminal hypertensive disease can gain admission to hospital-the group for which treatment achieves little.

The objectives of this study were twofold-firstly, to determine whether there is any evidence that the successful lowering of blood pressure in subjects with only mild or moderate hypertension could be expected to prevent or retard the progress of hypertensive cardiovascular disease; and, secondly, to devise an outpatient treatment programme for hypertension which would be appropriate for the social, economic, and educational circumstances of the majority of patients in the West Indies and the other parts of the world with a comparable background.

\section{Material and Methods}

In this report we give data from a hypertensive clinic which was set up at the University Hospital in Jamaica with these objectives in May 1967. An additional 40 patients studied at a rural health centre clinic will be reported on elsewhere.

Criteria for Selection of Patients.-Patients were admitted to the clinic in four treatment categories according to age and blood pressure levels (Table I). The age of the patient and a mean of three lying diastolic blood pressure levels (phase V) recorded after five minutes' rest and at intervals of at least one week determined the treatment category to which the patient was allocated. Subjects in categories 1 and 2 were divided at random between active drug and placebo and followed at maximum intervals of three months in the clinic. Allocation to a placebo treatment group was ethically justified since patients with these levels of blood pressure would not normally have received active treatment in the clinic. All patients in categories 3 and 4 received treatment with active drugs.

TABLE I-Drug and Treatment Categories

\begin{tabular}{|c|c|c|c|}
\hline Category & Age in Years & $\begin{array}{c}\text { Diastolic Pressure } \\
(\mathrm{mm} \mathrm{Hg})\end{array}$ & Treatment \\
\hline $\begin{array}{l}\cdots \\
\because \\
\cdots\end{array}$ & $\begin{array}{l}44 \text { or less } \\
45 \text { or over } \\
44 \text { or less } \\
45 \text { or over }\end{array}$ & $\begin{array}{l}\geqslant 95 \text { and }<110 \\
\geqslant 100 \text { and }<120 \\
\geqslant 110 \\
\geqslant 120\end{array}$ & $\begin{array}{l}\text { Active drug or placebo } \\
\text { Active drug or placebo } \\
\text { Active drug } \\
\text { Active drug }\end{array}$ \\
\hline
\end{tabular}

Grounds for exclusion (categories 1 and 2) were (a) evidence that hypertension was secondary to a surgically treatable condition; (b) cases currently receiving antihypertensive therapy; (c) cases with normally accepted indications for antihypertensive treatment (papilloedema, renal failure (blood urea over $60 \mathrm{mg} / 100$ $\mathrm{ml}$ ), or cardiac failure); (d) other serious disease or disability likely to be fatal or to prevent regular attendance and, in some instances, distance of domicile from the clinic; and (e) cardiovascular accident or myocardial infarction within the preceding three months.

Grounds for withdrawal from treatment categories 1 and 2 were mainly (a) persistent poor attendance or poor co-operation and (b) a consistent rise of diastolic blood pressure above $110 \mathrm{~mm} \mathrm{Hg}$ in category 1 or above 120 in category 2 or other clear indication for antihypertensive treatment.

Drugs.-The active drugs used were selected from guanethidine (Ismelin), debrisoquine sulphate (Declinax), bethanidine (Esbatal), and a chlorothiazide diuretic (Esidrex). The study was not primarily designed to test the relative effectiveness of any of these drugs but to assess the long-term effects of blood pressure control in whatever way this was achieved. Nevertheless, treatment in all cases was started with one or other of these three main hypotensive agents, a diuretic being added only if control was not adequate or was difficult.

Investigations and Laboratory Procedures. Investigations carried out at each hospital visit included urine analysis and lying and standing blood pressure (after the subject had been lying for a minimum of five minutes and standing for a minimum of one minute). The clinic nurse who recorded the blood pressure had no knowledge of the patient's treatment category or of the drug in use at the time of the visit. A simple questionnaire aimed at determining the presence or severity of side effects of drug therapy was given to each patient in the study at each visit to the clinic. At the beginning of treatment and at least once annually the following investigations were carried out on all patients: a 12-lead electrocardiogram; estimation of blood urea and electrolytes, chest $x$-ray examination, urine bacterial count, urine microscopy and culture, serum cholesterol estimation, and a glucose tolerance test. Intravenous pyelography was done only when there seemed to be special clinical indications.

Levels of Blood Pressure Control.-The level of standing diastolic pressure achieved was graded according to the age and treatment category of the patient. In each category the objective of treatment was to reduce the standing diastolic pressure to levels of $10 \mathrm{~mm} \mathrm{Hg}$ or more below the minimum point of entry into that category. For example, a standing diastolic pressure equal to or less than 85 in category 1 and equal to or less than 90 in category 2 was aimed at if this could be achieved without unacceptable side effects. This degree of control was considered good. If these levels could not be achieved without symptoms diastolic levels at any point below the minimum level for entry to a given category were regarded as satisfactory. Failure to achieve this was considered a poor response.

Follow-up.-The duration of follow-up of patients included in this study was between 12 months and three and a half years, with an average of 26 months. Details are given of only those patients whose duration of follow-up was more than 12 consecutive months. Drug treatment was dispensed in the clinic to minimize delays and to maintain patient collaboration. Patients were required to return all boxes of medication at each visit, and random tablet counts were carried out to assess the patient's reliability. In spite of its obvious limitations this procedure was of value in assessing lapses in patient cooperation. Except for periods of leave or illness the doctors and senior nurse in charge of the clinic were the same throughout the study.

\section{Results}

Fifty-six out of 64 patients $(87 \cdot 5 \%)$ admitted to categories 1 and 2 (Table II) and 81 out of $102(79.4 \%)$ admitted to categories 3 
and 4 (Table III) were followed for a minimum of 12 months. There was a noticeably high proportion of women in all categories.

The prevalence of radiological cardiac enlargement on initial $x$-ray examination in the four treatment categories is shown in Table IV. A cardiothoracic ratio greater than 1:2 was regarded as evidence of cardiac enlargement. This was found to be high in all categories-12\% in category $1,45 \%$ in category $2,48 \%$ in category 3 , and $83 \%$ in category 4 . The unexpectedly high rates, however, at the relatively modest blood pressure levels in categories 1 and 2 are of particular interest.

There were also high prevalence rates of electrocardiographic evidence of left ventricular hypertrophy (Sokolow Lyon (1949) criteria) (Table V) $-24 \%$ in category $1,51 \%$ in category 2 , $62 \%$ in category 3 , and $88 \%$ in category 4 . The unexpectedly high rates in categories 1 and 2 are again of interest.

Although chest $x$-ray examinations and electrocardiograms were repeated annually treatment of most patients was not long enough, nor were the numbers large enough, to merit analysis of these measurements.

There was no significant difference in the degree of control achieved with guanethidine, bethanidine, and debrisoquine (Table VI). In subjects in whom a change of drug had become necessary the drug in use at the time of assessment was the one used in the analysis of drug control. Out of a total of 104 patients the results were considered good in 63, satisfactory in 14 , and poor in 27. Mean daily dosages in categories 1 and 2 were guanethidine $67 \mathrm{mg}$ (range 20-150), debrisoquine $79 \mathrm{mg}$ (range 30-210), and bethanidine $91 \mathrm{mg}$ (range 30-300). In categories 3 and 4 the daily dosages were guanethidine $80 \mathrm{mg}$

TABLE II-Patients Admitted to Categories 1 and 2

\begin{tabular}{|c|c|c|}
\hline & $\begin{array}{l}\text { No. Admitted } \\
\text { to Study }\end{array}$ & $\begin{array}{l}\text { No. Followed for } \\
12 \text { Months or More }\end{array}$ \\
\hline $\begin{array}{ll}\text { Category } 1 & \begin{array}{l}\text { Men } \\
\text { Women }\end{array} \\
\text { Category } 2 & \cdots \\
\text { Men } & \cdots \\
\text { Women } & \cdots\end{array}$ & $\begin{array}{r}1 \\
24 \\
9 \\
30\end{array}$ & $\begin{array}{r}1 \\
20 \\
9 \\
26\end{array}$ \\
\hline $\begin{array}{lll}\text { Total } & \ldots & \ldots\end{array}$ & 64 & $56(87.5 \%)$ \\
\hline
\end{tabular}

TABLE III-Patients Admitted to Categories 3 and 4

\begin{tabular}{|c|c|c|}
\hline & $\begin{array}{l}\text { No. Admitted } \\
\text { to Study }\end{array}$ & $\begin{array}{l}\text { No. Followed for } \\
12 \text { Months or More }\end{array}$ \\
\hline $\begin{array}{l}\text { Category } 3\left\{\begin{array}{l}\text { Men } \\
\text { Women }\end{array} \text { Category } 4\left\{\begin{array}{l}\text { Men } \\
\text { Women }\end{array} .\right.\right.\end{array}$ & $\begin{array}{l}14 \\
24 \\
28 \\
36\end{array}$ & $\begin{array}{l}11 \\
16 \\
22 \\
32\end{array}$ \\
\hline $\begin{array}{llll}\text { Total } & \ldots & \ldots & \ldots\end{array}$ & 102 & $81(79.4 \%)$ \\
\hline
\end{tabular}

TABLE IV-Chest $X$-ray Results

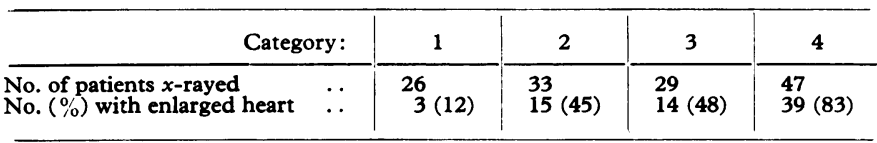

TABLE V-Electrocardiographic Results

\begin{tabular}{|c|c|c|c|c|}
\hline Category: & 1 & 2 & 3 & 4 \\
\hline $\begin{array}{l}\text { No. having electrocardiograms } . . \\
\text { No. (\%) with left ventricular } \\
\text { hypertrophy } \ldots\end{array}$ & $\begin{array}{l}26 \\
6(24)\end{array}$ & $\begin{array}{l}35 \\
18(51)\end{array}$ & $\begin{array}{l}29 \\
18(62)\end{array}$ & $\begin{array}{l}51 \\
45(88)\end{array}$ \\
\hline
\end{tabular}

TABLE VI-Drugs and Degrees of Control

\begin{tabular}{|c|c|c|c|c|c|c|c|c|c|}
\hline & & & \multicolumn{2}{|c|}{ Good } & \multicolumn{2}{|c|}{ Satisfactory } & \multicolumn{2}{|c|}{ Poor } & \multirow{2}{*}{ Total } \\
\hline & & & No. & $\%$ & No. & $\%$ & No. & $\%$ & \\
\hline $\begin{array}{l}\text { Guanethidine } \\
\text { Bethanidine } \\
\text { Debrisoquine }\end{array}$ & $\begin{array}{l}\cdots \\
\cdots\end{array}$ & $\begin{array}{l}\cdots \\
\cdots\end{array}$ & $\begin{array}{l}36 \\
14 \\
13\end{array}$ & $\begin{array}{l}67 \\
56 \\
52\end{array}$ & $\begin{array}{l}7 \\
1 \\
6\end{array}$ & $\begin{array}{r}13 \\
4 \\
24\end{array}$ & $\begin{array}{r}11 \\
10 \\
6\end{array}$ & $\begin{array}{l}20 \\
40 \\
24\end{array}$ & $\begin{array}{l}54 \\
25 \\
25\end{array}$ \\
\hline Total & .. & $\ldots$ & 63 & & 14 & & 27 & & 104 \\
\hline
\end{tabular}

(range 10-300), debrisoquine $94 \mathrm{mg}$ (range 30-210), and bethanidine $98 \mathrm{mg}$ (range 60-225).

The diastolic blood pressure changes in 30 placebo-treated patients and their individual follow-up are illustrated in Fig. 1. The degree and rate of rise in blood pressure are shown. There was a rise of diastolic pressure in most of the patients, and in five active treatment became necessary because of the levels reached. The comparable blood pressure changes in 26 patients treated with active drugs are given in Fig. 2. There were two in whom no significant fall of pressure could be achieved and three in whom an actual rise in mean pressure was recorded. The extent of the fall in blood pressure recorded in the remaining 20 patients is shown.

In all patients the blood pressure changes were calculated from the mean of the three initial pressures which determined the patient's treatment category and the mean of the final standing pressures recorded at the last three clinic visits.

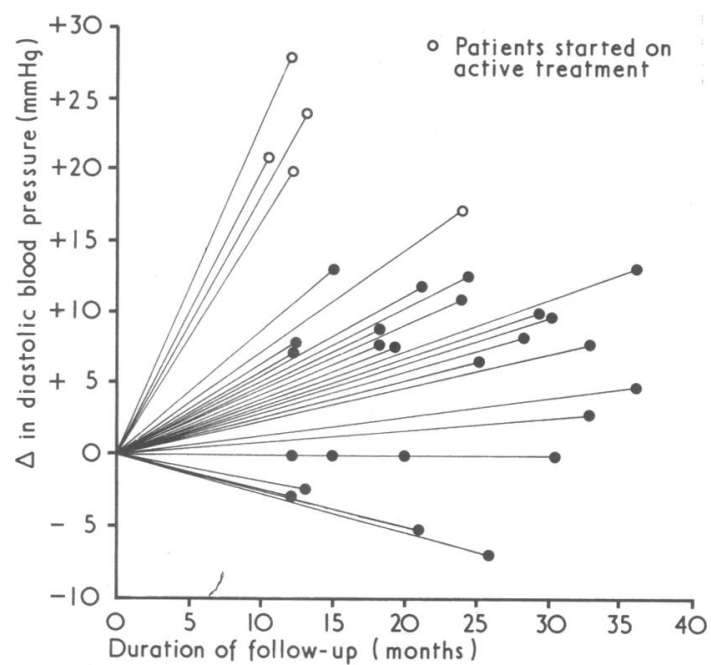

FIG. 1-Changes in diastolic blood pressure in patients receiving placebo.

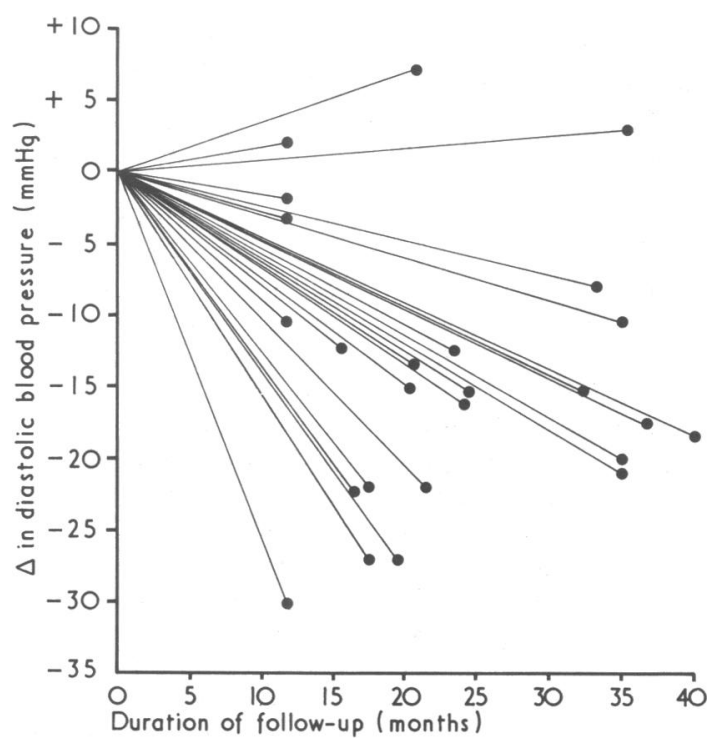

FIG. 2-Changes in diastolic blood pressure in patients treated with active drugs.

DEATHS

Eleven patients died during the trial (10 from groups 3 and 4 and one from group 2). In none was death thought to be attributable to the drugs being used or their side effects. Two patients died suddenly at home in circumstances which suggested the possibility of coronary thrombosis. In two further patients who 
died at home no reliable information could be obtained. Of the seven patients who died in hospital one died of clinical left ventricular failure, but necropsy was not performed. One death was due to subarachnoid haemorrhage, three were due to intracerebral bleeding, and two were due to ruptured abdominal aneurysm (one after operation). It is of interest that blood pressure control had been poor in five of these patients and that this in turn seemed to be due largely to poor patient collaboration.

\section{Discussion}

Blood pressure surveys in Jamaica, as in Western countries, have shown that blood pressure levels increase with age (Miall et al., 1962). In a recent 10-year follow-up of representative populations in South Wales Miall and Lovell (1967) obtained data which indicate that this relation to age may be more apparent than real and that it may be the blood pressure level attained by the individual at any given age rather than his age per se which is the most important determinant for this subsequent rise in blood pressure and its degree. Miall and Lovell's data would therefore suggest that recognition and successful treatment at early stages may prevent or retard the rise of blood pressure, which in the past has been thought to be due essentially to advancing age and therefore, to some extent at any rate, inevitable. This hypothesis was supported by Hamilton's (1966) study and by the findings of the Veterans Administration Cooperative Study Group (1967) in Washington, which have provided convincing evidence of the effectiveness of treatment of the less severe grades of hypertension in terms of mortality and morbidity. An added indication for early recognition and treatment may be the observation of Kass and Zinner (1969) that the well-known familial tendency which characterizes hypertension may be detected even in infancy or early childhood.

Mild hypertension is generally regarded as a benign and slowly progressive disorder. The high prevalence, however, of radiological and electrocardiographic evidence of cardiac enlargement in the present patients with mild hypertension suggests that significant cardiac changes may already have occurred in spite of only modest rises in blood pressure. Also the pronounced increases in blood pressure observed during placebo therapy indicate the rapidity with which progression to known high-risk levels of blood pressure may occur in untreated individuals.

Oglesby Paul (1971) gave data relating to the risks of mild hypertension in a study of 6,640 men aged 30 to 59 years when first seen. In the subjects with mild hypertension the risks with respect to coronary and cerebrovascular episodes were shown to be high numerically. His data are in accord with the observations of Evans and Rose (1971) that the main burden of illness associated with high blood pressure arises not from the relatively small number of severe cases but from the very large number of people with pressures which although above average are still within the range conventionally regarded as normal.

Although the numbers in the present study are small the findings provide presumptive indications of the benefits to be expected from the effective treatment of patients with mild hypertension. In view of the high risks known to be associated with the rates of rise and levels of blood pressure attained by a number of subjects in the placebo-treated group it seems evident that the early identification and treatment of such patients would be of value.

The factors which may affect the degree of blood pressure control that can be achieved in individuals or groups of patients are so variable that comparisons of our results with those of other published studies are difficult. Most studies accept as good control a reduction of standing diastolic blood pressure to $100 \mathrm{~mm} \mathrm{Hg}$ or less. Montuschi and Pickens (1962) found that $44 \%$ of the 25 patients in their series were controlled to this level. The proportion noted by Johnston et al. (1964) was $58 \%$ of 31 patients. Other studies include those of Dollery et al. (1960)- $43 \%$ of 80 patients-and Lowther and Turner (1963)$40 \%$ of 75 patients. In the present study $60 \%$ of the 81 patients in groups 3 and 4 who were followed for 12 months or more were controlled to diastolic levels of $100 \mathrm{~mm} \mathrm{Hg}$ or less.

Possibly the greatest degree of blood pressure control achieved in this series compared with other studies was not due to differences in severity of hypertension but to our clinic routine, which provided a personal and relaxed atmosphere in which waiting and inconvenience were reduced to a minimum, medical and nursing staff changes were few, and patient morale, confidence, and collaboration were high.

We have also compared the experience obtained at our blood pressure clinic with the results that were obtained when hypertensive patients were treated in general medical outpatient clinics in the hospital in the period immediately preceding the establishment of the blood pressure clinic. During this period, follow-up for more than 12 consecutive months was infrequently obtained-in only $20 \%$ of 50 consecutive patients whose records were examined. Blood pressure control to $100 \mathrm{~mm} \mathrm{Hg}$ or less was achieved in only $24 \%$ of these patients.

\section{Drugs}

With respect to the effectiveness and side effects of the drugs used our observations are not new. There was a relatively high incidence of diarrhoea on guanethidine, as noted by Prichard et al. (1968). On the other hand, its administration in a single daily dose is a great advantage in communities such as ours. Athanassiadis et al. (1966) drew attention to the greater rapidity and flexibility with which blood pressure control could be achieved by debrisoquine. Bath et al. (1967) made similar observations with respect to bethanidine. We were able to confirm these observations for both bethanidine and debrisoquine compared with guanethidine. These advantages, however, tended to be offset by the relative inconvenience of administration in three divided doses a day. On the whole there were no significant differences in the effectiveness with which good blood pressure control could be achieved by any of the three active drugs used.

This study was supported by a grant from the Tropical Medicine Research Board (scheme R-2086). It is a pleasure to record our thanks to Dr. A. D. Munro-Faure, of Burroughs Wellcome Research Laboratories, Dr. J. R. MacDougal, of Burroughs Wellcome \& Co. (Canada) Ltd., Dr. T. B. Binns, of Ciba Laboratories, and Dr. C. G. Burgess, of Roche Products Ltd., who provided all the drugs used in this study and also support for some clinic personnel. We are grateful for the help given by many persons during this study, but we would like to record our special indebtedness to Mrs. Phyllis Gibbs, who has been in charge of our hypertension clinic from its beginning in 1967, for her dedicated and thoughtful attention to its management.

\section{References}

Athanassiadis, D., Cranston, W. I., Juel-Jensen, B. E., and Oliver, D. O. (1966). British Medical fournal, 2, 732.

Bath, J., Pickering, D., and Turner, R. (1967). British Medical fournal, 4, 519. Bath, J., Pickering, D., and Turner, R. (1967). British Medical fournal, 4, 519.
Dollery, C. T., Emslie-Smith, D., and Milne, M. D. (1960). Lancet, 2, 381. Dollery, C. T., Emslie-Smith, D., and Milne, M. D. (1960). Lancet,
Evans, J. G., and Rose, G. (1971). British Medical Bulletin, 27, 37.

Freis, E. D. (1969). Milbank Memorial Fund Quarterly, 47, part 2, p. 153. Hamilton, M. (1966). In Antihypertensive Therapy, ed. F. Gross, p. 196. New York, Springer.

Johnston, A. W., Prichard, B. N. C., and Rosenheim, M. L. (1964). Lancet, 2,659 .

Kass, E. H., and Zinner, S. H. (1969). Milbank Memorial Fund Quarterly, 47, part 2, p. 143 .

Lowther, C. P., and Turner, R. W. D. (1963). British Medical fournal, 2, 776 Miall, W. E., Kass, E. H., Ling, J., and Stuart, K. L. (1962). British Medical Fournal, 2, 497.

Miall, W. E., and Lovell, H. G. (1967). British Medical fournal, 2, 660.

Montuschi, E., and Pickens, P. T. (1962). Lancet, 2, 897.

Paul, O. (1971). British Heart fournal, 33, Suppl., p. 116.

Prichard, B. N. C., Johnston, A. W., Hill, I. D., and Rosenheim, M. L. (1968). British Medical fournal, 1, 135.

Sokolow, M., and Lyon, T. P. (1949). American Heart fournal, 37, 161

Veterans Administration Cooperative Study Group on Antihypertensive Agents (1967). Fournal of the American Medical Association, 202, 1028. 